\title{
IMPLICAÇÕES JURÍDICAS NA ALTERAÇÃO DE PRENOME E GÊNERO \\ NO REGISTRO CIVIL DE TRANSEXUAL NÃO OPERADO
}

\author{
LEGAL IMPLICATIONS OF THE AMENDMENT GIVEN NAME AND GENDER \\ IN CIVIL REGISTRATION OF TRANSEXUAL NOT OPERATED
}

\author{
${ }^{1}$ Mariana Tamara de Lima \\ Oliveira \\ ${ }^{2}$ Luís Carlos Balbino \\ Gambogi
}

\section{RESUMO}

Pretende-se compreender a legalidade da retificação do registro civil do prenome e gênero de transexuais não submetidos à cirurgia de redesignação sexual. A ausência de tratamento legal desse tema, deixa a descoberto a pessoa que assume socialmente uma identidade sexual diversa do seu sexo biológico, o que demanda a submissão desta pretensão ao Órgão Judiciário, que está longe de consolidar um entendimento acerca da matéria. Serão analisados aspectos históricos e normativos, a fim de traçar o cenário atual em que esses pleitos se desenvolvem, e destacar os fundamentos normativos envoltos nesta problemática e que validam a retificação do registro civil.

Palavras-chave: Retificação, Registro civil, Transexuais

\begin{abstract}
It's intended to comprehend the legality of the rectification of the civil registry of the forename and gender from the transsexuals not submitted to a sex reassignment surgery. The absence of a legal treatment, leave uncovered people who assumes socially a varied sexual identity of their biologic sex, which demands a submission of this pretension to the judicial organ. It'll be analyzed the historical and legal aspects, in order to draft the scenario where those legal issues develop, and highlight the legal fundamentals covering this matter that validate the rectification of the civil registry.
\end{abstract}

Keywords: Words: rectification, Civil registry, Transsexuals

\footnotetext{
${ }^{1}$ Graduada em Direito pela Universidade -FUMEC. Belo Horizonte. Minas Gerais. Paralegal pela Capanema Reis Sociedade de Advogados, Belo Horizonte, Minas Gerais, (Brasil) Email: tutortreinamneto@ gmail.com

${ }^{2}$ Doutor em Filosofia do Direito pela Universidade Federal de Minas Gerais -UFMG,Belo Horizonte, Minas Gerais. Professor pela Universidade Fundação Mineira de Educação e Cultura -FUMEC, Belo Horizonte, Minas Gerais, (Brasil).
} 


\section{INTRODUÇÃO}

O presente trabalho científico critica a legalidade da alteração do prenome e do gênero do assento de nascimento de transexual não operado, analisando as implicações jurídicas para tal alteração, sob a égide da Constituição da República, dos Direitos da personalidade e da Lei de Registros Públicos.

A alteração de registro civil pleiteada pelo transexual é tema recente e amplamente discutido, todavia, inexiste lei específica no ordenamento jurídico brasileiro que regulamente essa retificação.

Nota-se que, nas decisões de retificação civil, podem surgir três possibilidades: dar procedência total, permitindo tanto a alteração de sexo quanto de prenome; dar procedência parcial, concedendo-se somente a alteração de prenome; dar improcedência total aos pedidos de modificação no registro.

As decisões que concedem ambos os pedidos baseiam-se nos Princípios Constitucionais da Igualdade e da Dignidade da Pessoa Humana, bem como nos direitos da personalidade, que tutelam os direitos e garantias individuais de toda pessoa humana, sobretudo, as minorias, como os transexuais. Os magistrados aferem que, no ordenamento jurídico, apesar de inexistir lei que autorize a retificação de registro civil, não há proibição legal expressa; portanto, é pertinente a concessão da autorização judicial que altera o prenome e o gênero do transexual, permitindo, assim, a adequação à nova realidade, mesmo não havendo cirurgia de troca de sexo, trazendo dignidade ao transexual, para que este exerça, livre e adequadamente, os atos de sua vida civil, sem passar por situações vexatórias ou discriminatórias.

Quando se é concedido parcialmente o pedido, é acolhido apenas a mudança de prenome, alegando os juízes que a Lei de Registros Públicos determina a alteração do prenome, quando expuser o seu portador à indignidade, desde que não seja prejudicado o sobrenome de família. Afirmam que, embora a Lei $\mathrm{n}^{\mathrm{o}}$. 6015/73 determine a imutabilidade do nome, há casos excepcionais, previstos legalmente, em que se permite a mudança de prenome. Dessa forma, baseando-se na Lei de Registro Público, bem como no direito da personalidade e nos princípios constitucionais, tais julgados consideram lícita somente a mudança do prenome do transexual, não concedendo, a mudança de gênero dos transexuais, por faltar-lhe respaldo legal. 
Nos julgados que dão improcedência total ao pedido, juízes baseiam sua decisão na falta de respaldo jurídico para retificação de registro de transexual.

Pesquisa-se, então, a legalidade da retificação do registro civil, através de doutrinas que discutem a licitude da retificação de nome e gênero do transexual não operado. Discutese, também, os direitos da personalidade, princípios constitucionais e a Lei de Registros Públicos no. 6015/73.

\section{HISTÓRIA}

A transexualidade é tema relativamente recente, sendo caracterizada pela medicina só no final do século XX. Anteriormente, este assunto era baseado apenas em lendas apresentadas pelos historiadores, como as que originam do Império Romano, da Sociedade Helenística ou da Europa Antiga, possibilitando pensar que a transexualidade era algo presente também em remotas eras, conforme diz Farina (1982).

O mesmo autor afirma que, na Idade Média, desvios do comportamento sexual, como travestismo, homossexualismo e fetichismo eram tidos como manifestações demoníacas, passíveis de perseguição e até mesmo condenação. Desde a época do Cristianismo até a Revolução Francesa, os comportamentos sexuais eram considerados fora da normalidade e de competência de inquisidores, exorcistas ou confessores, uma vez que inaceitáveis. Na Renascença, os desvios de conflito de identidade de gênero deixaram de ser possessões demoníacas, vício ou transgressão moral e religiosa, e passaram a ser compreendidos como doença - distúrbios mentais - ou apenas desvios da normalidade.

A palavra "transexual" apareceu pela primeira vez na literatura, em 1923, no trabalho de Hirschfeld, sem haver a distinção entre travestismo, homossexualismo e transexualismo, ele juntou todas essas espécies em um só gênero. Somente em 1949, o termo "transexual", expresso pelo doutor D. O. Cauldwell referiu-se ao estado em que o indivíduo deseja a mudança do sexo, segundo Pinto e Bruns (2009).

No entanto, foi Harry Benjamin, em Nova York, especialista nos estudos sobre transexualismo, quem divulgou a nova terminologia ao publicar, em 1966, o livro The Transexual Phenomenonin (O Fenômeno Transexual), com experiências documentadas da vida e cotidiano de alguns transexuais. Foi, então, após publicar este livro, considerado o "pai da transexualidade", pois a sua obra contribuiu para melhor compreensão sobre o tema (PINTO; BRUNS, 2009). 
A transexualidade figura-se como assunto recente também no cenário jurídico, sobretudo o brasileiro, tendo em vista que, segundo Sylvia Mendonça do Amaral (2003), um dos primeiros pedidos para mudança de sexo foi analisado apenas em 1980, no Tribunal do Rio Grande do Sul.

Somente na década de noventa, a transexualidade teve maior divulgação pela mídia brasileira, através do caso da modelo Roberta Close, que, apesar de ter se submetido à cirurgia de adequação sexual em 1989, travou uma longa batalha para ter reconhecido pelo Poder Judiciário o direito de mudança do sexo jurídico. Desde então, cresce o número de demandas que pleiteiam, nos tribunais brasileiros, a mudança de nome e gênero nos registros civis.

\section{O TRANSEXUALISMO}

Por ser tema problema complexo, torna-se necessário definir o que é sexo, para, então, entender o que é o transexualismo.

Não se pode definir o sexo de uma pessoa tomando-se apenas o aspecto físico ou anatômico; deve-se, pois, conjugar com outros fatores como o psicológico, o biológico ou o social.

A palavra sexo possui infinitos sentidos, podendo ser aplicada de diversas formas. Embora a gama de significados, sexo é algo muito complexo, para reduzir-se, somente, à genitália do indivíduo, conforme afirma Peres (2001).

O conceito de sexo, então, pode ser entendido como:

[...] o sexo é a resultante de um equilíbrio de diferentes fatores que agem de forma concorrente nos planos físico, psicológico e social. [...] Assim fatores genéticos, endócrinos, somatórios, psicológicos e sociais se integrampara definir a situaçãode uma pessoa em termos sexuais. (MARANHÃO, 1995. p. 127)

Então, há de se conjugar variados critérios para determinar o sexo de um indivíduo, analisando-o sob variadas classificações.

A seguir, apresenta-se a classificação de alguns tipos de sexo que, no presente trabalho, acredita ser o sexo psicossocial o mais importante para a caracterização de uma pessoa.

O sexo genético, também chamado de cromossômico, é determinado no exato momento da fecundação ovular. Peres (2001) afirma que se a constituição for de gametas 
homogamético $(\mathrm{XX})$, será um indivíduo do sexo feminino, ou, no caso de constituir-se em gametas heterogamético $(\mathrm{XY})$, será do sexo masculino.

Sexo legal, chamado também de jurídico (ARAÚJO, 2000), é tido como aquele constante no registro civil de nascimento do indivíduo, efetuado junto ao Cartório de Registro Civil das Pessoas Físicas, conforme determina Peres (2001)

Da certidão de nascimento, o Estado reconhece oficialmente o nascimento do indivíduo, concedendo publicidade ao fato jurídico. Conforme preceitua a Lei $\mathrm{n}^{\mathrm{o}}$. 6015, de 31 de dezembro de 1973, que dispõe sobre os registros públicos, presume-se ter relativa veracidade o que consta na certidão, devido à fé pública emanada dos documentos emitidos pelos Cartórios de Registros Civis.

Estabelece-se o sexo legal, também conhecido como jurídico, de acordo com os aspectos biológicos apresentados pelo indivíduo, resumindo-se na análise da aparência externa da genitália. (PERES, 2001). Assim, é comum que no registro civil, esteja constado o sexo do indivíduo de acordo com a genitália que o mesmo apresenta.

O sexo de criação vincula-se ao meio em que a criança cresce e se desenvolve, com a participação de pais, familiares, educadores, religiosos, ou seja, todos que convivem com a criança, de modo que aqueles que estão mais próximos possuem maior responsabilidade no processo da educação infantil da mesma, afirma Peres (2001)

Sexo de criação, também designado como "sexo social", é o resultado da educação recebida pela criança para que desenvolva o seu papel, seja feminino ou masculino, assim diz Vieira (1996).

Há casos em que o sexo social pode não estar de acordo ao sexo biológico, como os intersexuais que possuem genitália ambígua, ou até mesmo em casos que a criança é vista e criada de forma oposta ao sexo que apresenta.

Já o sexo psicossocial, depende de interações genéticas, fisiológicas e psicológicas que se formaram dentro de uma atmosfera sociocultural em que a pessoa vive. A sua formação depende da atuação de diversos elementos; no entanto, manifesta-se o sexo psicossocial no indivíduo através da sua identidade de gênero. Sendo assim, é o produto final da percepção que o indivíduo possui de si mesmo, seja como homem ou mulher, segundo Peres (2001).

Este tipo de sexo, também conhecido como sexo psicológico, apresenta diversos fatores - físicos, sociais e psicológicos - que podem atuar sobre os comportamentos e reações humanas definidos como masculino e feminino; logo, os processos educativos, de aculturamento e de adaptação social não são os únicos determinantes para o ajuste bio- 
psíquico-social, por existir desvios psicológico-sexuais que levam a alguns indivíduos possuírem uma estrutura psicológica imprópria ao seu sexo biológico, diz Maranhão (1995).

O sexo psicossocial ou psicológico representa o que a pessoa sente ser, independente do que ela seja sob o ponto de vista biológico e civil. O sexo psicológico seria, então, determinado ainda na gestação, no sistema nervoso da criança, não havendo semelhanças com o sexo biológico, e podendo ser até imutável, conforme Souza (2010).

O sexo psicossocial trata de questões psicológicas, divergindo dos demais já apresentados, pois envolvem elementos que fogem de questões meramente biológicas ou físicas; logo, por razões que a ciência desconhece, um indivíduo biologicamente perfeito (com sexo genital interno e externo) pode não se sentir adequado sexualmente, como no caso dos transexuais (PERES, 2001).

Há de se falar, também da identidade de gênero, a fim de se classificar o transexualismo. Peres (2001) esclarece que a identidade de gênero é o sentimento do indivíduo quanto à sua identificação pessoal, seja como homem ou como mulher, também chamada de identidade sexual por Oliveira (2003). Constitui-se por variadas características presentes no sexo genético, legal, de nascimento e de criação, não se tratando apenas de fatores biológicos, mas também de outras interações.

Assim, embora cada individuo tenha uma formação íntima, revela-se aos outros, através do papel sexual exercido na sociedade. Percebe-se, então, que o comportamento sexual faz parte também da educação em família, na escola, no religioso, dentre outros.

Pode-se dizer que o aprendizado e o condicionamento social influenciam na formação da identidade de gênero, embora a constituição do psicológico seja, na maioria das vezes, determinante. Normalmente, a regra é a identidade sexual ser semelhante com a aparência da genitália externa do indivíduo, havendo compatibilidade entre o sexo biológico e a identidade de gênero; no entanto, há casos em que inexiste tal compatibilidade, como no transexualismo (PERES, 2001).

O transtorno de identidade de gênero é uma ordem psicológica, já que a pessoa nasce com um sexo, mas se identifica como se pertencesse de outro, considerando isto uma total desarmonia (VIEIRA, 2008).

O transexual, então, possui uma identidade sexual adversa à sua condição física, pois não se aceita da na sua forma biológica, nem com as atribuições sociais pertinentes ao sexo designado (PINTO, BRUNS, 2009).

A pessoa considerada dentro dos padrões da normalidade sexual é aquela em que os 
fatores biológicos estão harmonizados com os psicológicos e sociais. Assim, o indivíduo possui características sincronizadas, qual seja: sexo morfológico, identidade de gênero e papel sexual que seguem na mesma direção sexual. Na sociedade brasileira, tal protótipo é chamado de heterossexual, conforme Peres (2001).

Há de se frisar que, embora não satisfeitos com seu sexo e corpo físico, não é regra que todos os transexuais tenham que se submeterem á cirurgia de transegenização. Na maioria das vezes, os transexuais pleiteiam apenas a mudança de nome e gênero, sem que tenham que se submeterem a tal procedimento.

Define-se a transexualidade, também conhecida como desordem de identidade, como a contradição entre corpo e subjetividade, por haver inadequação do corpo físico do indivíduo à sua identidade sexual (BENTO, 2006).

Sobre o surgimento da transexualidade, há quatro teorias, a saber:

A primeira, genética, acredita emuma variação cromos sômica; a segunda, fenotípica acredita na tendência transexual em razão do biótipo da pessoa; já a terceira, psicológica entende que a fixação do padrão sexual se daria pela expectativa que os pais impõemá pessoa antes mesmo que ela tenha consciência do seu próprio eu, bemcomo emrazão de variações hormonais dentro do seio materno; por fim, aquarta teoria, eclética, que é a mais aceita, entende que a fixação do quadro transexual se dá coma conjugação de fat ores, genéticos, fenotípicos e psicogênicos (SOUZA, 2010, p.115)

Doutrinariamente, costuma-se classificar o transexualismo em primário e secundário. No primeiro, o indivíduo apresenta vontade inequívoca e veemente da vontade de mudar o sexo; no segundo, o indivíduo oscila entre o homossexualismo (característica ou qualidade de um ser humano que sente atração física, estética e/ou emocional por outro ser do mesmo sexo ou gênero) e o travestismo (caracteriza-se por vestir roupas do sexo oposto com o objetivo principal de obter excitação sexual e de criar a aparência de pessoa do sexo oposto), conforme Peres (2001). O presente trabalho somente tratará do transexualismo primário, com as designações "transexualismo" ou "transexualidade".

\section{DA PROTEÇÃO JURÍDICA AOS TRANSEXUAIS}

O transexual está inserido na sociedade, e detém todos os direitos e garantias assegurados pelo texto constitucional pátrio, sobretudo os que estão expressos no art. $5^{\circ}$, possuindo pleno direito à existência, integridade física, tratamento humano e não degradante, intimidade, privacidade, entre outros. 
Neste sentido, o Estado deve buscar um caminho que pressuponha a felicidade de seus cidadãos. Os princípios constitucionais, dispostos na $\mathrm{CR} / 88$, firmaram o compromisso estatal na busca da felicidade, ao eleger fundamentos como o Estado Democrático de Direito, a dignidade da pessoa humana e a promoção do bem comum, afirma Araujo (2000).

No presente trabalho, discute-se a proteção jurídica ao transexual, haja vista ser sujeito de direito, dotado de plenos direitos assegurados pelo ordenamento legal, sobretudo pela Constituição de 1988, com força nos princípios da igualdade e da liberdade e no fundamento da dignidade da pessoa humana.

A dignidade da pessoa humana, um dos fundamentos previsto no art. $1^{\circ}$, inciso III da Constituição de 1988, garante a todos os indivíduos o livre desenvolvimento de sua personalidade. Trata-se, portanto, do alicerce constitucional que fundamenta e legitima a garantia do exercício pleno de sua identidade de gênero, privacidade, liberdade e felicidade.

Ressalta-se que a dignidade da pessoa humana foi consagrada como valor constitucional supremo, do qual irradia todos os direitos fundamentais do indivíduo, cujo reconhecimento constitui a manifestação necessária da primazia da dignidade humana, uma das mais destacadas diretrizes hermenêuticas do ordenamento jurídico.

Além disso, o Poder Constituinte impõe que não se deve apenas observar e proteger esse valor supremo, mas também deve-se promover os meios necessários ao alcance das condições mínimas indispensáveis de uma vida digna e ao pleno desenvolvimento da personalidade.

José Afonso da Silva ensina que "dignidade da pessoa humana é valor supremo que atrai o conteúdo de todos os direitos fundamentais do homem, desde o direito à vida" (SILVA, 2007, p. 105).

A dignidade da pessoa humana é relevante a ponto de respeitar à integridade física e psíquica das pessoas, admissão da existência de condições mínimas materiais e patrimoniais para a vida digna, além do respeito da existência da liberdade e igualdade (SILVA, 2006).

Há de se falar também no direito de não ser discriminado, que encontra-se intimamente vinculado às bases do Estado Democrático de Direito, cujo paradigma traz a noção de pluralismo, cujo pressuposto consiste no respeito e na proteção de vida distinta daquela considerada como padrão pela maioria da sociedade. Ademais, todas as normas jurídicas devem direcionar no sentido de não apenas tornar a vida humana possível, mas, sobretudo, digna. 
A dignidade da pessoa humana é como a unificação de direitos e garantias fundamentais, por serem inerentes às personalidades humanas, conceitua Alexandre de Moraes (2005). E ainda afirma:

A dignidade é um valor espiritual e moral inerente à pessoa, que se manifesta singularmente na autodeterminação consciente e responsável da própria vidaeque traz consigo a pretensão ao respeito por parte das demais pessoas, constituindo-se um mínimo invulnerável que todo es tatuto jurídico deve assegurar, de modo que, somente excepcionalmente, possamser feitas limitações aos direitos fundamentais, mas sempre sem menosprezar a neces sária estima que merecem todas as pessoas enquanto seres humanos (MORAES, 2005, p.16).

A dignidade da pessoa humana é, então, fundamento constitucional, por ter a Constituição Federal reconhecido o ser humano como centro de todo o sistema jurídico. As normas devem ser feitas para a realização existencial da pessoa humana, garantindo-lhe que seus direitos fundamentais sejam respeitados, a fim de conceder-lhe não só vida digna, como também o livre desenvolvimento de sua personalidade.

Afere-se que os transexuais, como pessoas humanas existentes na sociedade brasileira, possuem o direito de viver com dignidade, como qualquer outro ser humano, devendo o Estado proporcionar-lhes todas as condições necessárias para que tenham o direito preservado à vida digna.

Diante do exposto, indaga-se: aquele que vive em conflito permanente na condição de inadequação da identidade sexual possui vida digna? Será digno não poder ser reconhecido pela sociedade com o sexo ao qual se identifica? Teria dignidade o ser humano que possui nome e sexo divergente do que vive?

Pelo Princípio da Dignidade da Pessoa Humana, previsto na Constituição de 1988 como fundamento, demonstra-se a necessidade de que haja efetiva tutela jurídica aos transexuais, porque inexiste previsão, no ordenamento legal, acerca da alteração de gênero e nome no registro civil.

Também o conceito de liberdade humana consiste na possibilidade de coordenação consciente dos meios necessários à realização da felicidade pessoal, compreendendo a liberdade como poder de autodeterminação, porque o homem tem escolha, por si mesmo, do seu comportamento pessoal.

A ideia de liberdade, além de englobar elementos objetivos e subjetivos:

[...] é poder de atuação sem deixar de ser resistência à opressão; não se dirige contra, mas em busca, em perseguição de alguma coisa, que é a felicidade pessoal, que é subjetiva e circunstancial, pondo a liberdade, pelo seu fim, em harmonia com consciência de cada um, com o interesse do agente. Tudo o que impedir aquela coordenação dos meios é contrário à liberdade (SILVA, 2006, p. 234) 
O princípio da legalidade liga-se à noção de liberdade, como garantia individual, no inciso II, do art. $5^{\circ}$ da $\mathrm{CR} / 88$, que se expressa: "ninguém será obrigado a fazer, ou deixar de fazer alguma coisa senão em virtude de lei”.

A partir do conceito de que a pessoa humana tem a liberdade de buscar sua felicidade, conforme the necessário, desde que não haja proibição legal, possibilita compreender que cada um, ao seu modo, pode autodeterminar sua condição pessoal, sem interferência estatal ou de terceiros, incluindo-se, neste ponto, a questão da transexualidade, que, evidentemente, inexiste vedação legal; portanto, com força no princípio da liberdade, o transexual não deve sofrer nenhum tipo de impedimento na busca de sua felicidade, quer pela coletividade, quer pelo poder estatal.

Nesse entendimento, pode-se afirmar:

A construção de uma sociedade livre, justa e solidária não pode ter significado sem $\mathrm{o}$ atendimento dos anseios de seus indivíduos. O sentido de liberdade, justeza e solidariedade pass a pelo alcance pessoal da felicidade. Os indivíduos têmdireito,para alcançar uma sociedade livre, justa e solidária, a buscar o caminho de sua felicidade. Nesse passo, o transexual teria o direito de buscar o meio de ser mais feliz, de eliminar a contradição exis tente em sua vida (ARAÙJO, 2000, p. 100)

Compreende-se, assim, o livre exercício do direito de ação, posto que o transexual deve buscar a chancela estatal para adequar o seu registro civil, alterando-o de modo a espelhar a realidade, com o intuito de tornar-se uma pessoa íntegra e respeitada, uma vez que é tutelado o direito individual de liberdade

Ora, se inexiste obste legal, o Estado tem o dever e o poder de conceder à pessoa transexual o livre exercício de seu direito de liberdade, bem como a toda coletividade, oferecendo possibilidades para a alteração dos seus documentos civis, a fim de estar em conformidade com a identidade psicológica.

Mais uma vez, demonstra-se, sob a égide da Constituição da República, a necessidade de haver a tutela jurídica aos transexuais, com base no Direito Individual de Liberdade, que deve ser analisado, conjuntamente, ao Princípio da Dignidade da Pessoa Humana e ao direito de igualdade. Dessa forma, somente poderá alcançar vida digna e mais feliz, se a minoria transexual for tratada de forma diferenciada pelo Estado.

Pelo princípio da isonomia, quando o art. $5^{\circ}$ da Constituição de 1998, prescreve a igualdade dos homens perante a lei, significa que interessa ao aplicador do direito, os direitos 
e deveres concedidos aos indivíduos da coletividade por meio dos textos legais. Afere-se, doutrinariamente, que a igualdade posiciona-se em conformidade com o já dito por Aristóteles, para o qual o princípio da igualdade consistiria em "tratar igualmente os iguais e desigualmente os desiguais na medida em que eles se desigualam" (BASTOS, 2002, p.292).

Ensina Sarlet (2001) sobre o princípio da igualdade:

[...] encontra-se diretamente ancorado na dignidade da pessoa humana, não sendo por outro motivo que a Declaração Universal da ONU consagrou que todos os seres humanos são iguais emdignidade e direitos. Assim, constitui pressuposto essencial para o respeito da dignidade da pessoa humana a garantia da isonomia de todos os seres humanos, que, portanto, não podem ser submetidos a tratamento discriminatório e arbitrário, razão pela qual não podemser toleradas a escravidão, a discriminação racial, perseguições por motivo de religião, sexo, enfim toa e qualquer ofensa ao princípio isonômico na sua dupla dimensão formal e material. (SARLET, 2001, p.89)

No mesmo sentido, considera jurídica a igualdade, proclamada na Constituição de 1998, já que busca a equalização dos desiguais pela outorga de direitos sociais substanciais, segundo Silva (2007).

“A democracia é confirmada na valorização da maioria, sem o desprezo da minoria. Quando falamos em Estado Democrático, falamos da vontade majoritária, mas não da ditadura da maioria”, elenca Araújo (2000, p. 2).

A igualdade prevê, expressamente, não existir distinção de qualquer natureza e qualquer forma de discriminação. Pode-se, então, perfeitamente, estender essa igualdade em relação à orientação sexual, uma vez que não se admite qualquer tipo de preconceito.

Por todo o exposto, fica demonstrado que a tutela específica aos transexuais está prevista, mesmo que de maneira implícita, na Constituição de 1988, através do Direito Individual à Igualdade e, conforme mencionado anteriormente, do Princípio Fundamental da Dignidade da pessoa humana; logo, é dever do Estado Democrático de Direito conceder um tratamento isonômico à minoria transexual, através de um tratamento diferenciado, a fim de que não sofram nenhum tipo de discriminação pela sociedade e, então, possibilite uma vida digna, além de buscar a realização da felicidade dos seus indivíduos. Embora exista uma maioria hegemônica, para haver equidade, a minoria transexual deve ser considerada pelo Estado Democrático pluralista, ainda que seus interesses e valores sejam adversos.

Para efeito de proteção do indivíduo contra os abusos do Estado, incluem-se na categoria de direitos fundamentais, aqueles referentes à liberdade e ao direito de ação. "De 
outro lado, consideram-se direitos da personalidade os mesmos direitos, mas sob o ângulo das relações particulares, ou seja, da proteção contra outros homens" (BITTAR, 2008, p. 23).

Os direitos da personalidade tratam dos direitos subjetivos que tutelam a pessoa humana, com a valorização dos aspectos existenciais do homem, indispensáveis à proteção da dignidade e integridade das pessoas; assim, é necessário que tenham o caráter de essencialidade, uma vez que são direitos que, se inexistissem, a pessoa não existiria como tal, segundo Peres (2001).

Além do previsto em lei, os direitos da personalidade possuem características, tais como: são absolutos por serem oponíveis erga omnes e impõe à coletividade o dever de respeitá-los; são imprescritíveis por não haver prazo extintivo; são expatrimoniais por não se sujeitarem à apreciação econômica; são impenhoráveis por não poderem ser objeto de penhora; e são vitalícios por extinguirem-se somente com a morte.

Portanto, são impostas garantias constitucionais que impõem condutas positivas ao Estado, para que sejam assegurados os direitos da personalidade que se distinguem das liberdades públicas, porque são, respectivamente, as condutas negativas e positivas impostas à coletividade e ao Estado.

Classificam-se os direitos da personalidade, que devem conter aspectos fundamentais, a saber: a integridade física (incluindo mo direito à vida, ao corpo, à saúde ou inteireza corporal), a integridade intelectual (direitos à autoria científica e literária, liberdade religiosa e de expressão, entre outras manifestações dom intelecto) e a integridade moral ou psíquica (direito à privacidade, ao nome, à imagem, dentre outros.).

Com base no exposto, pode-se afirmar que o transexual, assim como toda pessoa humana da sociedade brasileira, tem o direito personalíssimo de solicitar a alteração de seu registro civil, para que este se identifique com sua identidade sexual. Em consequência, tornase dever do Estado tutelar suas necessidades, criando ações que possibilitem a efetiva adequação da pessoa transexual e, da mesma forma, não proibindo ou dificultando o auxílio para sua realização como ser humano.

A Carta de Princípios de Yogyakarta - Princípios da Aplicação de Legislação Internacional de Direitos Humanos em relação a Orientação Sexual e a Identidade de gênero, versa, em seu $3^{\circ}$ princípio que "ninguém poderá ser obrigado a submeter-se a procedimentos de médicos, inclusive à cirurgia de resignação sexual, esterilização ou tratamento hormonal, como um requisito para reconhecimento legal de identidade e gênero.”

Neste sentido, o transexual: 
[...] vive um conflito permanente. Acredita pertencer a um sexo que não é seu. Tem vontade de viver como mulher, se homem, e como homem, se mulher. Não se trat a de algo que permita a um tratamento psicológico ou qualquer outro tipo de ajuda. salvo a cirurgia, compos terior acompanhamento médico e psicológico.O trans exual poderá optar por outros tratamentos, mas não atingirá os anseios de sua alma, qual seja, mudar o sexo. [...] ele convive com problemas na es cola, no trabalho, na vida social, no lazer e em suas relações amorosas. Tudo decorrente da falta de identificação, da impossibilidade de aceitar a própria condição, entre seu sexo real e o sexo desejado. (ARAÙJO, 2000, p. 104)

Para a presente reflexão, há de se analisar o direito á identidade pessoal, que é aquele que permite que uma pessoa seja reconhecida por outrem como reconhece a si mesma. É, pois, o direito concedido a alguém de ter a sua própria imagem ideal, segundo os valores que crê, ou seja, o direito à identidade interior, construído a partir de um conjunto de traços, presentes na personalidade, que se misturam e se sobrepõem entre si, segundo Vieira (2008).

Entende a referida autora:

Evidentemente, o sexo constitui umdos caracteres da identidade pess oal. A doutrina discute a pos sibilidade de se conceder o direito à identidade sexual. Para alguns, a transexualidade se enquadra perfeitamente na possibilidade de dis posição do corpo. No entender de outrem principalmente doutrinadores italianos, pode-se falar do direito da pess oa ao sexo real, por ser este impres cindível componente da pessoa. (VIEIRA, 2008, p. 227)

Conclui-se, pois, que, a obrigação imposta ao Poder Público, no tocante à retificação do registro civil do transexual, consiste no mais concreto reconhecimento da dignidade da pessoa humana, além da efetivação do direito de não ser discriminado, a fim de que possa alcançar a sua felicidade e realização como pessoa humana.

\section{DA ALTERAÇÃO DO REGISTRO CIVIL DE TRANSEXUAL}

Questiona-se se as decisões judiciais que autorizam ou negam os pedidos dos transexuais para alterar o prenome e gênero em seus assentos civis, estão respaldadas pelo ordenamento jurídico brasileiro.

$\mathrm{O}$ art. 348 do Código Civil veda alterações nos assentos civis, havendo ressalvas em situações restritas, ao determinar que "ninguém pode vindicar estado contrário do que resulta do registro de nascimento, salvo provando-se erro ou falsidade do registro" (BRASIL, 2002). Além disso, o sistema jurídico brasileiro elenca o princípio da imutabilidade do nome, faltando respaldo legal para a pretensão do transexual que busca a retificação de nome e gênero em seu registro de nascimento. 
O sistema jurídico pátrio, atualmente, tornou-se aberto, composto de princípios e regras, em que as normas jurídicas constroem-se juntamente com o caso concreto, consoante o entendimento de Souza (2010).

Neste sentido:

O Direito atual vive a superação do positivis mo jurídico, a crise do Direito Civil, a descodificação e a Constitucionalização do Direito. Fala-se em repersonalização, com a dignidade da pessoa erigida ao centro do ordenamento jurídico pela Constituição da República de 1988, junto ao paradigma do Estado Democrático de Direito (SOUZA, 2010, p.112)

No Brasil, pode-se afirmar que o sistema jurídico deixa de ser fechado, ao que se refere às questões privadas, para abarcar as situações em que as respostas não foram previstas, encontrando-se, dentro desta nova ordem, o lugar cabível às minorias da sociedade ou "os excluídos pelo Direito tradicional" (SZANIAWSKI, 1988, p. 27).

Ademais, exige-se, muitas vezes, a apresentação de documentos públicos como condição para o exercício de inúmeros atos da vida civil, como a compra de uma casa, negociação de abertura de conta e aquisição de contratos bancários, matrícula em estabelecimento de ensino, atendimento em hospitais, entre inúmeros outros atos. Koichi Kameda de Figueiredo Carvalho anota que:

[...] o objetivo exis tencial da pes soa trans exual não é a mudança de sexo, no sentido de modificação de sua genitália e demais transformações corporais, mas antes tero seu reconhecimento social como pertencente ao gênero identificado. Essas modificações corporais, acompanhadas pela reprodução de papéis socialmente atribuídos ao gênero a que julga pertencer o indivíduo, integram o processo de desenvolvimento de sua identidade. (CARVALHO, 2009, p.466)

Para reconhecer-se em sociedade e, assim, ter a devida inclusão social, torna-se necessária a alteração do registro civil. É, então, imprescindível portar documentos que retratem a realidade, pois persiste o risco de situações vexatórias, que deprecia o transexual perante outrem, devido à aparência sexual que diverge do que está expresso em seus documentos.

Pode-se, então, afirmar:

[...] durante e, principalmente, após o tratamento, as modificações físicas vão s e acentuando e a identidade de gênero literalmente ganha corpo. Contudo, não há alteração simultânea e, por vezes, sequer posterior, da qualificação civil dos trans exuais, que continuam a portar documentos que contêm nome e sexo não condizentes com a pessoa que passou a existir como resultado do tratamento. Em cons equência, mais severos são os constrangimentos, a ridicularização, o estigma e a 
discriminação do transexual, que não raro é acusado de apresentar documentos falsos. Grandes são as dificuldades para obter trabalho e superar a exclusão social sempre sofrida (BARBOZA; SCHRAMM apud CARVALHO, 2009, p. 466)

A polêmica criada em torno da concessão da alteração do registro civil de gênero e prenome de um transexual não operado, reside no fato da inexistência de legislação específica no ordenamento brasileiro, fazendo com que as decisões, levadas pelos interessados ao Poder Judiciário, fiquem à mercê do entendimento pessoal de cada julgador. Evidentemente, a decisão favorável deverá estar pautada em princípios jurídicos e não em regras positivadas.

Quanto à natureza jurídica do pedido de alteração de gênero e prenome, fundamentase nos direitos da personalidade. Os direitos personalíssimos, considerados direitos subjetivos, são decorrentes da qualidade do ser humano que possui bens e valores que the são inerentes em seus aspectos: físico, moral e intelectual. Sem dúvida, amparados no Princípio da Dignidade da Pessoa Humana, os direitos da personalidade protegem não só bens, como também valores essenciais do indivíduo que tutelam o seu direito ao nome, à capacidade e ao estado civil.

Em princípio, pode-se afirmar que os dados registrados numa certidão civil são imutáveis, só podendo sofrer alguma alteração se obedecidos os ditames previstos no ordenamento jurídico, especialmente o que está previsto na Lei $n^{\circ}$. 6015/75, conhecida como Lei de Registros Públicos (LPL); todavia, a vida de uma pessoa sofre mudanças, por passar por diversas etapas e fases, modificando o estado das pessoas. Tais mudanças de estado, por possuírem relevância para o direito como casamento, separação, divórcio ou óbito, necessitam ser anotados nos Cartórios de Registro Civil, para darem publicidade dos fatos jurídicos do interesse da coletividade.

Hoje vige no Brasil a regra da imutabilidade do nome; porém, a própria Lei de Registros Civis prevê a possibilidade de alteração do prenome no art. 58, caput, da Lei ${ }^{\circ}$ 6015/75, uma vez que se admite sua substituição por apelidos públicos notórios.

Acerca da imutabilidade do nome, com sentido social residente na identificação do indivíduo frente à sociedade, Caio Mário da Silva Pereira (2005) conclama:

\footnotetext{
Sem descer ao debate abstrato, o nos so direito, não obstante o silencio do Código Civil de 1916, sempre pendeu para definir o nome como umdireito, designativo do indivíduo, e fator de identificação. Comtais finalidades, destacam-se no nome civil dois aspectos: público e privado, e, neste sentido, diz-se que é um direito e um dever. Envolve simultaneamente umdireito subjetivo e uminteresse social. Ocorre que o interesse social apenas subsistirá coma manutenção do prenome, pois aquele cidadão que requer a alteração do registro, há muito já tem sido conhecido e reconhecido socialmente pelo nome que pleiteia constar do as sento de nascimento. A manutenção do prenome incondizente só caus ará situação ridícula e vexatória para
} 
o titular do documento, e risível e inacreditável para o terceiro interess ado. O que causa espanto à sociedade é uma mulher com nome de homem e vice-versa. A alteração do prenome deve ocorrer em conseqüência da de estado sexual, em prol daqueles direitos da personalidade. (PEREIRA, 2005. p. 235)

Embora seja de ordem pública, a inalterabilidade do nome pode sofrer exceção, se houver manifesto interesse de uma pessoa ou existir benefício social com motivação comprovada. No caso dos transexuais, encaixa-se quanto ao uso de nome diverso, já que o nome civil é a real individualização da pessoa perante a sociedade, e se, por ventura, tal pessoa passou a ser conhecida por prenome que não corresponde ao que consta em seu registro, deve-se, então, alterá-lo.

O pedido de alteração de sexo requer maior esforço argumentativo para o sucesso do pleito, tendo em vista que "não há uma regra jurídica expressa autorizativa, sendo necessário buscar respostas junto aos princípios jurídicos”. (SOUZA, 2010, p. 123).

Ademais, se houver um pedido judicial cuja norma jurídica inexista, não poderá o magistrado deixar de julgar sob o argumento de inexistência de lei específica, pois o artigo $4^{\circ}$ da Lei de Introdução ao Código Civil (BRASIL, 1942) determina que "quando a lei for omissa, o juiz decidirá o caso de acordo com a analogia, os costumes e os princípios gerais de direito".

Portanto, conforme Souza (2010), ainda que inexistam regras jurídicas amoldadas aos casos pleiteados em juízo, a hermenêutica moderna preceitua que os princípios e as regras se referem ao "âmbito do dever ser e, portanto, são normas" (LORENZETTI, 1988 apud SOUZA, 2010, p. 124); logo, são aptos para o embasamento de decisões judiciais.

Também com base na Lei de Introdução ao Código Civil (1942), no art. 5º o magistrado, ao julgar, deve-se ater aos fins sociais a que a lei se dirige e às exigências do bem comum; logo, deve o juiz, na aplicação da lei ao caso concreto, conceder ao seu titular o direito a vida digna.

Assim exposto, afere-se que a concessão da alteração do sexo legal no registro civil do transexual não operado tem fundamento na autenticidade dos registros públicos, pois, ao permitir que alguém porte um documento que não autentica a realidade, é expô-lo, indevidamente, à situação pública vexatória, já que se pode alegar falsidade, visto que o nome corresponderá a um gênero e o sexo legal a outro.

O surgimento de Resoluções e Portarias de natureza administrativa, para dar uma solução viável aos transexuais, evidencia que há necessidade que seja criada uma lei que 
regulamente a permissão da alteração do registro civil, com relação ao sexo e prenome, para que, da mesma forma, possa o Estado dar uma solução às divergências de decisões judiciais.

Nesta toada, o Tribunal de Justiça do Estado de Minas Gerais já se pronunciou pelo deferimento da retificação no registro civil de transexual, pelo argumento que "Às vezes, é necessário que a lei se dobre ante a realidade porque o Direito tem compromisso com a realidade; deve satisfação às exigências de justiça que nascem da realidade." (TJMG Agravo de Instrumento 1.0521.13.011034-4/001, Relator(a): Des.(a) Luís Carlos Gambogi, $5^{\text {a }}$ CÂMARA CÍVEL, julgamento em 24/10/2013, publicação da súmula em 30/10/2013). Para finalizar, analisaremos a seguir um acórdão proferido pelo Tribunal de Justiça do Estado do Rio Grande do Sul, deferindo a retificação no registro civil de transexual, independente de cirurgia de transgenitalização:

\begin{abstract}
APELAÇÃO. RETIFICAÇÃO DE REGISTRO CIVIL. TRANSEXUALISMO. TRAVESTISMO. ALTERAÇÃO DE PRENOME INDEPENDENTEMENTE DA REALIZAÇÃO DE CIRURGIA DE TRANSGENITALIZAÇÃOO. DIREITO À IDENTIDADE PESSOAL E À DIGNIDADE. CONFIRMAÇÃO DE SENTENÇA DE PRIMEIRO GRAU. ACOLHIMENTO DE PARECER DO MINISTÉRIO PÚBLICO DE SEGUNDO GRAU.

A demonstração de que as características físicas e psíquicas do indivíduo, que se apresenta como mulher, não estão emconformidade comas características que o seu nome masculino representa coletiva e individualmente são suficientes para determinar a sua alteração. A distinção entre transexualidade e travestismo não é requisito para a efetivação do direito à dignidade. Tais fatos autorizam mes mo sem a realização da cirurgia de trans genitalização, a retificação do nome da requerente para conformá-lo com a sua identidade social. Pronta indicação de dispositivos legais e constitucionais que visa evitar embargo de declaração com objetivo de prequestionamento. (Apelação Cível No 70022504849, Oitava Câmara Cível, Tribunal de Justiça do RS, Relator: Rui Portanova, Julgado em 16/04/2009)
\end{abstract}

Assim, o pedido para alteração de nome e gênero, deverá ser pleiteado perante a Vara de Registros Públicos, através de jurisdição voluntária, por se tratar de retificação de registro civil. Deve-se ouvir o Ministério Público, como fiscal da lei, ter audiência para oitiva do requerente e de testemunhas, bem como realizar estudo psicossocial.

\title{
6 CONCLUSÃO
}

A presente discussão, como colocado no preâmbulo, não buscou inovar acerca do tema, mas objetivou reconstruir o entendimento da problemática do transexual no Brasil, tomando por base o que já foi proposto em outros trabalhos apresentados. 
Buscou-se, assim, comprovar o direito dos transexuais e a licitude da possibilidade jurídica da alteração de sexo e prenome de transexual não operado, sobretudo com o respaldo do fundamento da Dignidade da Pessoa Humana, nos princípios de liberdade e de igualdade e dos direitos da personalidade, principalmente, porque inexiste, legalização ou vedação, no ordenamento jurídico pátrio, para o tratamento adequado à questão transexual.

Percebe-se, assim, que cabe, então, a cada magistrado que se depara diante de um pedido de retificação de registro civil de transexual não operado, abandonar a tradicional dogmática, para, através da hermenêutica, aplicar os princípios jurídicos ao caso concreto, concedendo o direito de alteração do prenome e sexo legal conforme pleiteia o interessado, com o fim maior de trazer pacificação social.

Decerto, o magistrado possui o poder-dever de negar ou permitir a alteração do registro civil; todavia, a negativa da alteração de prenome e sexo ao transexual retira-lhe a chance de adquirir dignidade, porque o impele a viver, por toda a vida, com documentos civis que estão em desacordo com a sua identidade sexual, impedindo-o de exercer plenamente sua vida civil com liberdade e igualdade.

A alteração do estado sexual e do prenome no registro e documentos civis é tão necessária quanto os tratamentos que são fornecidos para a adequação sexual d transexual. Ora, se existe tratamentos fornecidos pelo Estado, é inegável que se deva, da mesma forma, dar condições para que o indivíduo, após os tratamentos realizados para sua adequação sexual, exerça seus atos da vida civil dignamente; portanto, torna-se incongruente o Estado fornecer um tratamento adequado para o transexual proceder sua adequação física e, ao mesmo tempo, inadequado quando nega a correção do nome de sexo em seus documentos civis.

É temerário e indigno viver com documentos que não retratem a real identificação sexual de um indivíduo, colocando o portador à mercê da discriminação e rejeição sociais. Frise-se que existe alto grau de suicídio e mutilação, quando não possibilitada a adequação sexual aos portadores de transexualismo. Não obstante, conforme diz a própria ciência que estuda a biologia do ser humano, em trechos já citados acima, a definição de sexo vai muito além do órgão genital.

Não se pode negar que o assunto é polêmico, todavia, deve-se refletir que, na maioria dos casos, ser transexual traz intenso sofrimento a pessoa, acima de tudo pelo preconceito, logo, deve ser entendido como um ser humano desarmonizado e em conflito que necessita de amparo e compreensão, não só do Estado, como também de toda a coletividade.

Assim, dar ao transexual não operado o direito de alterar o prenome e o sexo no seu registro é conceder-lhe vida digna, consubstanciada no respeito à diferença, permitindo-lhe 
viver conforme sua vontade e identidade de gênero, dando efetividade ao Estado Democrático de Direito brasileiro.

\section{REFERÊNCIAS}

AMARAL, Sylvia Mendonça do. Manual Prático dos Direitos de Homossexuais e Transe xuais. São Paub: Edições Inteligentes, 2003.

ANDRADE, Carlos Drummond de. Boitempo II. 1987. Disponível em:

$<$ http://www.sosestudante.com/resumos-b/boitempo-1-e-2-carlos-drummond-deandrade.html>. Acesso em: 28 de mar. de 2016.

ARAÚJO, Luiz Alberto David. A Proteção Constitucional do Transexual. São Paulo: Saraiva, 2000.

ARBENZ, Guilherme Osvaldo. Medicina Legal e Antropologia Forense. Rio de Janeiro: Atheneu, 1988, 409p.

BARBOZA, Heloisa Helena. Princípios do Biodireito. In: BARBOZA, H. H; MEIRELLES, J. M. L.; VICENTE, P. B. (Org). Novos temas de Biodireito e Bioética. Rio de Janeiro: Renovar, 2003, p. 49-81.

BASTOS, Celso Ribeiro. Curso de Direito Constitucional. São Paulo: Celso Bastos Editor, 2002.

BENTO, B. A reinvenção do corpo: sexualidade e gênero na expe riência transexual. Rio de Janeiro: Garamond. 2006

BITTAR, Carlos Alberto. Os direitos da personalidade. 7. ed. Rio de Janeiro: Forense Universitária, 2008.

BRASIL. Decreto-Lei no. 4657, de 4 de setembro de 1942. Lei de Introdução ao Código Civil B rasileiro. 1942. Disponível em: <htps:www.planalto.gov./civil_03/decr eto-lei/del4657.htm>. Acesso em: 28 de mar. de 2016.

BRASIL. Lei n ${ }^{\circ}$ 10406/2002 de 10 de janeiro de 2002. Código Civil Brasileiro. 2002.

Disponível em: <http//www.planalto.gov.br/ccivil/leis/2002/L10406.htm>. Acesso em: 28 de mar. de 2016

BRASIL, Constituição (1998). Constituição da República Federativa do B rasil. 9. ed. rev. amp. e atual. São Paulo: Revista dos Tribunais. Brasília: Senado, 1998.

BRASIL. Conselho Federal De Medicina. Resolução no 1.652, de 6 de novembro de 2002. (Online). Dispõe sobre a cirurgia de transgenitalismo e revoga a resolução CFM n n $^{\circ}$ 1.482/97. Disponível em: <http//www.portalmedico.org.br/resolucoes/cfm/2

002/1652_2002.htm>. Acesso em: 28 de mar. de 2016. 
BRASIL. Lei n. 6015, de 31 de dezembro de 1973. Dispõe sobre os registros públicos, e dá outras providências. Disponível em $<\mathrm{http} / / \mathrm{www}$.planalto.gov.br/ccvil_0

3/leis//L6015.htm>. Acesso em: 28 de mar. de 2016.

BRASIL. Tribunal de Justiça De Minas Gerais. Agravo de Instrumento no. 1.0521.13.011034-4/001. Relator: Luís Carlos Gambogi. Belo Horizonte, 24 de outubro de 2013. Retificação de Registro de Nascimento. Transexual. Disponível em <http//www.tjmg. jus.br/juridico/jt_/juris>. Acesso em: 28 de mar. de 2016.

BRASIL. Tribunal De Justiça do Rio Grande Do Sul. Apelação Cível 70022504849. Relator: Rui Portanova. Porto Alegre, 16 de abril de 2009. Retificação de Registro Civil. Disponível em < $\underline{\text { www.tjirs.gov.br}}$ >. Acesso em: 28 de mar. de 2016.

CANOtilho, J.J. Gomes e MOREIRA, Vital. Constituição da República Portuguesa Anotada, 3. ed. Coimbra: Coimbra, 1984.

CARVALHO, Koichi Kameda de Figueiredo. Transexualidade e cidadania: a alteração do registro civil como fator de inclusão social. Revista Bioética. Brasîla: Conselho Federal de Medicina, DF. v. 17, n. 3, 2009.

FARINA, Roberto. Trans exualismo: do homem à mulher normal através dos estudos de intersexualidade e das parafilias. São Paulo: Novalunar, 1982.

MARANHÃO, Odon Ramos. Curso Básico de Medicina Legal. 7. ed. São Paulo: Malheiros, 1995.

MORAES, Alexandre de. Direito Cons titucional. 5. ed. São Paulo: Atlas, 2005.

MURARO, R. M; Boff, L. Feminino e mas culino: uma nova consciência para o encontro das diferenças. Rio de janeiro: Sextame, 2002.

PEREIRA, Caio Mário da Silva. Instituições de Direito Civil., 21. ed. rev. e atual. Rio de Janeiro: Forense, 2005. v.I.

PINTO, M. J. ; BRUNS, M. A. T. Vivência Transexual. O corpo desvela seu drama. Campinas: Átomo, 2009.

PERES, Ana Paula Ariston Barion. Transexualis mo: O Direito a uma nova Identidade Sexual. Rio de Janeiro: Renovar, 2001.

OLIVEIRA, Alexandre Miceli Alcântara de Oliveira. Direito de Autodeterminação Sexual. São Paulo: Juarez de Oliveira, 2003.

SILVA, José Afonso. Curso de Direito Constitucional Positivo. 28. ed. São Paulo: Malheiros, 2007.

SARLET, Ingo Wolfgang. Dignidade da Pessoa Humana e Direitos Fundamentais. Porto Alegre: Livraria do Advogado. 2001. 
SOUZA, Iara Antunes de Souza. Apontamentos para uma decisão judicial de alteração do nome e sexo no registro Civil do transexual operado. In: FIUZA, C.; SÁ, M. F. F. S.;

NAVES, B. T. O (Org.). Direito Civil - Teoria e Prática no Direito Privado - Atualidades IV. Belo Horizonte: Del Rey. 2010. p. 111-135.

SZANIAWSKI, Elimar. Limites e possibilidades do dire ito de re de signação do estado sexual. São Paulo: Editora Revista dos Tribunais, 1998. 34p.

TEPEDINO, Gustavo. Temas de Direito B rasileiro. 2. ed. Rio de Janeiro: Renovar, 2001.

TREVISAN, João Silvério. Devassos no Paraíso - A homossexualidade no Brasil, da colônia à atualidade. 3. ed. São Paulo: Record, 2000.

VIEIRA, Tereza Rodrigues. Mudança de sexo: aspectos médicos, psicológicos e jurídicos. 1. ed. São Paulo: Santos, 1996. 